\title{
Limited production of sulfate and nitrate on front-associated dust storm particles moving from desert to distant populated areas in northwestern China
}

\author{
Feng Wu ${ }^{1}$, Daizhou Zhang ${ }^{2}$, Junji Cao ${ }^{1,3}$, Xiao Guo ${ }^{1,4}$, Yao Xia ${ }^{1,4}$, Ting Zhang ${ }^{1}$, Hui Lu ${ }^{5}$, and Yan Cheng ${ }^{3}$ \\ ${ }^{1}$ Key Laboratory of Aerosol Chemistry \& Physics and State Key Laboratory of Loess and Quaternary Geology, \\ Institute of Earth Environment, Chinese Academy of Science, Xi'an, China \\ ${ }^{2}$ Faculty of Environmental and Symbiotic Sciences, Prefectural University of Kumamoto, Kumamoto, Japan \\ ${ }^{3}$ Institute of Global Environmental Change, Xi' an Jiaotong University, Xi'an, China \\ ${ }^{4}$ School of Tropical Eco-Environment Protection, Hainan Tropical Marine University, Sanya, China \\ ${ }^{5}$ Institute of Desert Meteorology, China Meteorological Administration, Urumqi, China \\ Correspondence to: Feng Wu (kurt_wf@ieecas.cn) and Daizhou Zhang (dzzhang@pu-kumamoto.ac.jp)
}

Received: 4 October 2016 - Discussion started: 5 December 2016

Revised: 2 November 2017 - Accepted: 3 November 2017 - Published: 6 December 2017

\begin{abstract}
Sulfate and nitrate compounds can greatly increase the hygroscopicity of mineral particles in the atmosphere and consequently alter the particles' physical and chemical properties. Their uptake on long-distance-transported Asian dust particles within mainland China has been reported to be substantial in previous studies, but the production was very inefficient in other studies. We compared these two salts in particles collected from a synoptic-scale, mid-latitude, cycloneinduced dust storm plume at the Tengger Desert $\left(38.79^{\circ} \mathrm{N}\right.$, $\left.105.38^{\circ} \mathrm{E}\right)$ and in particles collected in a postfrontal dust plume at an urban site in $\mathrm{Xi}^{\prime}$ an $\left(34.22^{\circ} \mathrm{N}, 108.87^{\circ} \mathrm{E}\right)$ when a front-associated dust storm from the Tengger Desert arrived there approximately $700 \mathrm{~km}$ downwind. The results showed that the sulfate concentration was not considerably different at the two sites, while the nitrate concentration was slightly larger at the urban site than that at the desert site. The estimated nitrate production rate was $4-5 \mathrm{ng} \mathrm{\mu g}^{-1}$ of mineral dust per day, which was much less than that in polluted urban air. The adiabatic process of the dust-loading air was suggested to be the reason for the absence of sulfate formation, and the uptake of background $\mathrm{HNO}_{3}$ was suggested to be the reason for the small nitrate production. According to our investigation of the published literature, the significant sulfate and nitrate in dust-storm-associated samples within the continental atmosphere reported in previous studies cannot be confirmed as actually produced on desert dust particles; the contribution from locally emitted and urban min-
\end{abstract}

eral particles or from soil-derived sulfate was likely substantial because the weather conditions in those studies indicated that the collection of the samples was started before dust arrival, or the air from which the samples were collected was a mixture of desert dust and locally emitted mineral particles. These results suggest that the production of nitrate and sulfate on dust particles following cold fronts is likely limited when the particles move from the desert to populated areas within the continent. For an accurate quantification of sulfate and nitrate formed on long-distance-transported desert dust particles at downwind populated areas in eastern China, dust collection efforts are indispensable to minimize any possible influence by locally emitted particles or at least to ensure that the samples are collected after dust arrival.

\section{Introduction}

Mineral dust particles constitute a substantial fraction of atmospheric aerosol mass and play various roles in atmospheric physics and chemistry (Bi et al., 2011; Dentener et al., 1996; Fu et al., 2009; Sokolik and Toon, 1996; Tegen et al., 1996). Dust particles at their source areas are mainly composed of quartz, clays, micas, feldspars, carbonates (primarily calcite, $\mathrm{CaCO}_{3}$ ) and other minor minerals (Usher et al., 2003). While suspended, they may be altered by the up- 
take of gases and smaller particles and by surface reactions. Laboratory studies have demonstrated the formation of sulfate and nitrate on dust particles upon exposure to reactive gases such as $\mathrm{NO}_{x}, \mathrm{HNO}_{3}, \mathrm{NO}_{3}, \mathrm{~N}_{2} \mathrm{O}_{5}$ and $\mathrm{SO}_{2}$ (Usher et al., 2003). The formation of salts on the particles can enhance the solubility of the particles, lower their effective deliquescence relative humidity (RH) and alter their size and physical state in association with atmospheric conditions (Semeniuk et al., 2007). These changes in turn feed back into the activities of dust particles in various chemical and physical processes in the atmosphere (Bauer and Koch, 2005), such as the enhancement of bioavailable iron (Meskhidze, 2003) and the removal of acidic gases in the atmosphere (Dentener et al., 1996; Dong et al., 2016; Zhang and Carmichael, 1999).

Field studies have shown different results regarding the formation of sulfate and nitrate on dust particles, and some results are contradictory. Many studies reported substantial sulfate and nitrate on the surface of Asian dust particles after the particles were transported over long distances in the atmosphere (Cao et al., 2003; Huang et al., 2010; Li and Shao, 2009; Mori, 2003; Nie et al., 2012; Nishikawa et al., 1991; Qi et al., 2006; Ro et al., 2005; Sun et al., 2010, 2004; Y. Wang et al., 2005, 2007; Wu and Okada, 1994; Zhao et al., 2011). In contrast, an early study of Zhang and Iwasaka (1999) found that sulfate and nitrate were rarely formed on Asian dust particles that had been transported over a long distance in inland China after about 2 days. A study at the Taklimakan Desert pointed out that in some cases the content of sulfate in dust particles might not change even when the particles traveled over a long distance. The dust particles contained substantial sulfate ( $\sim 4 \%$ by mass), which was from the surface soil (Wu et al., 2012). It was also found that, for a dust plume lofted from the surface by a synoptic mid-latitude cyclone, the plume did not mix significantly with adjacent air parcels polluted by anthropogenic sources; the dust plume and the polluted air were separated as two air parcels by the cold front associated with the cyclone (Bates et al., 2004; Tsai et al., 2014; Wang et al., 2013; Zhang et al., 2005). Some measurements of the chemical composition of longdistance-transported dust particles have also shown that most of the dust particles were not altered chemically and were externally mixed with species produced in the air via gasto-particle reactions, such as sulfate and nitrate (Denjean et al., 2015; Song et al., 2005). These results leave us with a question: why are there so many different rates of sulfate and nitrate production during dust transport to polluted areas?

In April 2014, we collected a series of atmospheric particle samples during a cyclone-induced dust storm at the eastern edge of the Tengger Desert, which is one of the most significant sources of Asian dust (J. Wang et al., 2012; Zhang et al., 2003). We also collected a series of samples at Xi'an, a large city in northwestern China when a dust storm from the Tengger Desert passed there after traveling about $6 \mathrm{~h}$ following a cold front. In this study, we compare the concentrations and mass fractions of sulfate and nitrate in the samples at the two sites and examine the production of nitrate and sulfate on desert dust particles after the particles were transported from the desert to the populated area in an attempt to understand the chemistry and aging on dust.

\section{Particle collection and analysis}

The observation site at the Tengger Desert was located at an active sand dune at a location called Tonggunao'er along the northeastern rim of the desert $\left(38.79^{\circ} \mathrm{N}, 105.38^{\circ} \mathrm{E}\right.$; Fig. 1). The closest village, with a population less than 200 , is about $5 \mathrm{~km}$ to the east of the site and the nearest city is Bayan Hot (Inner Mongolia Autonomous Region, China) about $35 \mathrm{~km}$ to the east of the site (Fig. S1 in the Supplement). Anthropogenic pollutants from the village and the city may arrive at the site if the wind direction is from the east. Backward trajectories of air masses (Fig. S2) and the simulation (Fig. S3a) of the online Chemical Weather Forecasting System (CFORS; developed with open access online by NIES and Kyushu University, Japan: http://www-cfors.nies.go.jp/ $\sim$ cfors/index-j.html) showed that a dust storm was induced by a synoptic-scale, mid-latitude cyclone in the southwestern part of Mongolia on 23 April 2014. The resulting dust plume was then transported southeastward and passed the sampling site on the morning of 24 April (Fig. S3a).

Observations were carried out between 06:30 BST (Beijing standard time: GMT + 08:00) and 15:00 BST on 24 April 2014. Particles were collected using a homemade filter pack sampling system, which consisted of one Teflon front filter for collecting particulate matter and one back filter for the collection of gas-phase species. The flow rate of $16.7 \mathrm{~L} \mathrm{~min}^{-1}$ was controlled with a mass flow controller (SmartTrak 50; Sierra). The filters were changed every $2 \mathrm{~h}$, and the collection of the fourth sample was stopped when it started to snow (Table 1). Field blank filters were prepared and obtained by mounting filters in a sampling system in a similar way to the particle collection for $2 \mathrm{~h}$ without pumping air. Right after the sample collection of each filter, the filter was put into a polystyrene petri dish, which was in turn sealed in a plastic bag and stored in a refrigerator at $-1{ }^{\circ} \mathrm{C}$ until subsequent analyses. Meteorological conditions including surface pressure, temperature, relative humidity, wind speed and wind direction were monitored with a weather tracker (Kestrel 4500; Kestrelmeters). The cold front passed the site between 04:00 and 04:30BST on 24 April, which was characterized by a rapid decrease in relative humidity, a sudden change in the wind direction from south to north, an increase in wind speed and a gradual increase in pressure (Fig. 2a). Therefore, all samples were collected after the passage of the cold front. This sample collection ensured that mineral particles collected on the filters were dominated by dust particles from the desert, and possible influence of anthropogenic pollutants from the village or the city was suppressed. 
Table 1. Summary of weather conditions during the sample collection.

\begin{tabular}{|c|c|c|c|c|c|c|}
\hline \multirow{2}{*}{$\begin{array}{l}\text { Samples } \\
\text { ID }\end{array}$} & \multirow{2}{*}{$\begin{array}{r}\text { Sampling time } \\
\left(\mathrm{BST}^{\mathrm{c}}\right)\end{array}$} & \multirow{2}{*}{$\begin{array}{r}\text { Pressure } \\
(\mathrm{hPa})\end{array}$} & \multirow{2}{*}{$\begin{array}{r}\text { Temperature } \\
\left({ }^{\circ} \mathrm{C}\right)\end{array}$} & \multirow{2}{*}{$\begin{array}{l}\mathrm{RH} \\
(\%)\end{array}$} & \multicolumn{2}{|c|}{ Wind } \\
\hline & & & & & Direction & Speed $\left(\mathrm{m} \mathrm{s}^{-1}\right)$ \\
\hline \multicolumn{7}{|c|}{ Tengger Desert (24 April 2014) } \\
\hline $\mathrm{T} 1$ & $06: 32-08: 32$ & $870.2-872.5$ & $9.5-11.0$ & $30-35$ & NW & $5.7-13.6$ \\
\hline $\mathrm{T} 2$ & $08: 42-10: 42$ & $872.4-874.7$ & $8.0-9.4$ & $31-37$ & NW & $5.6-11.4$ \\
\hline $\mathrm{T} 3$ & $10: 51-12: 51$ & $875.2-876.7$ & $5.5-7.7$ & $31-39$ & NW & $6.0-14.6$ \\
\hline $\mathrm{T} 4^{\mathrm{a}}$ & $13: 02-15: 03$ & $876.2-878.1$ & $-1.4-4.8$ & $40-97$ & NW & $5.8-12.3$ \\
\hline \multicolumn{7}{|c|}{ Xi'an (1 May 2014) } \\
\hline $\mathrm{X} 1$ & $07: 16-09: 16$ & $965.6-968.1$ & $17.6-19.6$ & $63-72$ & $\mathrm{~W}$ & $0-1.8$ \\
\hline $\mathrm{X} 2$ & 09:20-10:20 & $968.2-969.7$ & $19.5-21.7$ & $45-67$ & NW & $0-2.5$ \\
\hline $\mathrm{X} 3$ & $10: 22-11: 22$ & $970-971.7$ & $21.2-22.2$ & $39-50$ & NW & $0.5-3.2$ \\
\hline$X 4^{b}$ & $11: 27-12: 27$ & $971.7-972.7$ & $20.1-21.3$ & $40-43$ & NW & $0.6-3.4$ \\
\hline $\mathrm{X} 5$ & $12: 28-14: 28$ & $972.7-973.5$ & $20.0-20.7$ & $38-42$ & NW & $0.4-2.9$ \\
\hline X6 & $14: 38-16: 38$ & $972.4-973.2$ & $19.0-21.6$ & $38-47$ & NW & $0-5.4$ \\
\hline $\mathrm{X} 7$ & $16: 43-19: 43$ & $972.5-973.1$ & $18-21.8$ & $38-48$ & NW & $0-3.0$ \\
\hline
\end{tabular}

\footnotetext{
a Not suitable for comparison because of snow and the results from this sample were excluded for further analysis.

b Not available for analysis because the collection system was blown down by wind.

c Beijing standard time ( $8 \mathrm{~h}$ prior to GMT).
}

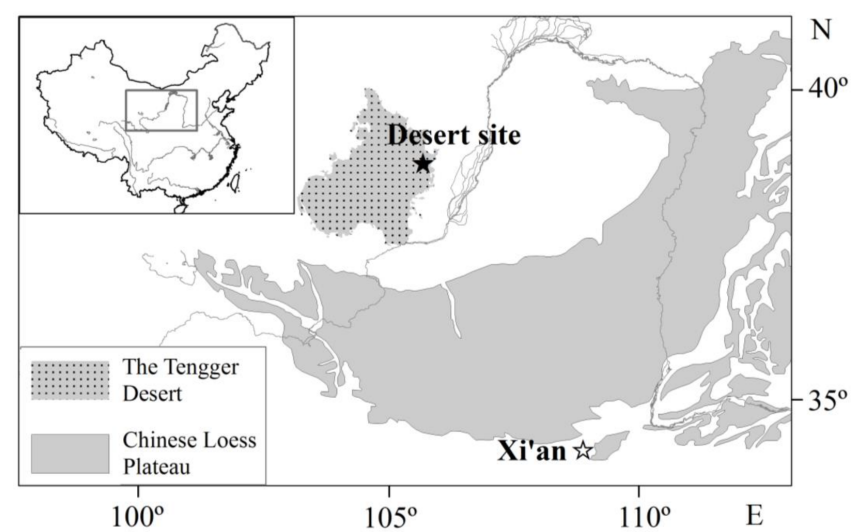

Figure 1. Location of the sampling sites. Also shown is the Chinese Loess Plateau.

$\mathrm{Xi}$ 'an $\left(34.22^{\circ} \mathrm{N}, 108.87^{\circ} \mathrm{E}\right)$ lies in central China, approximately $700 \mathrm{~km}$ from the Tengger Desert (Fig. 1). The observation in Xi' an was carried out on the roof of a building ( $10 \mathrm{~m}$ above the ground) on the campus of the Institute of Earth Environment. The institute is located in the southwestern area of the city, and its surroundings are residences, streets and office buildings. There are no large, continuous sources of anthropogenic pollutants such as factories or agriculture fields near the institute. Previous studies at this site have revealed that the local pollutants are mainly from traffic and the particulate pollutants mainly include particles from vehicle engines, road dust and construction dust, all of which have been characterized by contents of crustal elements, sul- fate, organic matter, nitrate and ammonium (R.-J. Huang et al., 2014; Zhang et al., 2011).

Particles were collected on 1 May 2014 when dustloading air passed Xi' an. Backward trajectories of air masses (Fig. S2) and the CFORS simulation (Fig. S3b) showed that, similar to the dust storm observed at the Tengger Desert, this dust storm was also induced by a cyclone in the southwestern part of Mongolia and moved southeastward (Fig. S3b). It passed the site of the Tengger Desert on the evening of 30 April and arrived at Xi' an on the morning of 1 May. Particle collection was carried out between 07:00 and 19:00 BST on 1 May. The same sampling system and the same type filters as those used for the particle collection at the desert site were used. Samples were collected at a time interval of 1 or $2 \mathrm{~h}$. In total, seven samples were obtained from the dust storm approach to its dissipation (Table 1). Each sample filter was put into a polystyrene petri dish, which was in turn sealed in a plastic bag and stored in a refrigerator at $-1{ }^{\circ} \mathrm{C}$ until subsequent analyses. Meteorological conditions were monitored by the Kestrel 4500 weather tracker. The sudden decrease in relative humidity showed that the arrival of the cold front of the cyclone occurred between 09:30 and 11:30 BST (Fig. 2b). Therefore, the first sample was collected before the arrival of the cold front, the second and third samples were collected in the frontal air, and the fourth, fifth and sixth samples were collected after the passage of the cold front. Unfortunately, the fourth sample was not available for analysis because the collection system was blown down by wind when this sample was collected. The concentrations of $\mathrm{SO}_{2}$ and $\mathrm{NO}_{2}$ were measured by using a UV fluorescence analyzer (Ecotech; model EC9850) and a chemiluminescence analyzer (Thermo; model 42i) and were recorded in units 

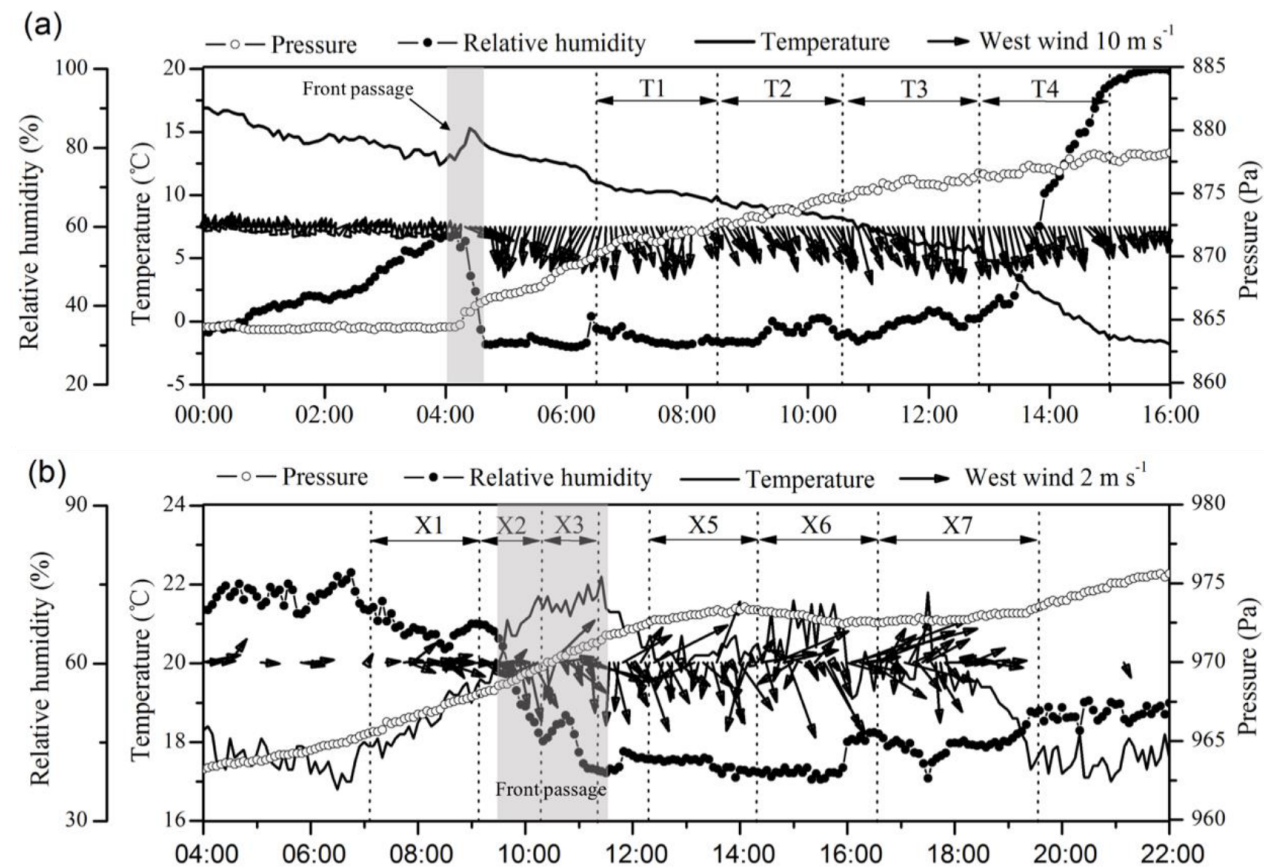

Figure 2. Surface pressure, temperature, relative humidity (RH) and wind during the sampling periods at the desert site (a: 24 April 2014 04:00-15:00 BST) and at the Xi' an site (b: 1 May 2014 04:00-12:00 BST). Also shown are the front passage (shaded bars) and the durations of sample collections (Table 1).

of ppb at a time interval of $5 \mathrm{~min}$. The lowest detection limit was approximately $0.04 \mathrm{ppb}$ for $\mathrm{SO}_{2}$ and $0.4 \mathrm{ppb}$ for $\mathrm{NO}_{2}$. Since the dust occurring in $\mathrm{Xi}$ ' an had the same source and a transport route similar to that at the desert site (Figs. S2, S3), the comparisons between the samples collected at the desert site and the Xi' an site can show changes in dust particles during the transport although the samples were not from the same dust event.

Teflon-membrane filter samples were equilibrated in a temperature- and relative-humidity-controlled environment $\left(20-23^{\circ} \mathrm{C}\right.$ and $35-45 \% \mathrm{RH}$, respectively) before gravimetric analysis to minimize particle volatilization and aerosolliquid water interferences. Filters were weighed before and after sampling using an ME5-F electronic microbalance (Sartorius; Göttingen, Germany) with a sensitivity of $\pm 0.001 \mathrm{mg}$. The precision of multiple weighings for unexposed and exposed filters was smaller than \pm 0.010 and $\pm 0.015 \mathrm{mg}$, respectively. Filters were exposed to a low-level radioactive source $(500 \mathrm{pCi}$ of polonium-210) before sample weighing to remove static charge. Mass concentrations were calculated with the difference in weight before and after sampling and the volume of sampled air. Half of each filter was analyzed to quantify the water-soluble components in particles. Each sampled filter was initially wetted with $200 \mu \mathrm{L}$ of ethanol. Water-soluble components were extracted by ultrasonic agitation in $10 \mathrm{~mL}$ of distilled water. The extraction solution was filtered with $0.45 \mathrm{~mm}$ pore size microporous membranes, and then the filtrate solution was stored at $4{ }^{\circ} \mathrm{C}$ until subsequent analyses. An ion chromatograph (Dionex DX-600) was used to quantify sulfate $\left(\mathrm{SO}_{4}^{2-}\right)$, nitrate $\left(\mathrm{NO}_{3}^{-}\right)$, chloride $\left(\mathrm{Cl}^{-}\right)$, sodium $\left(\mathrm{Na}^{+}\right)$, potassium $\left(\mathrm{K}^{+}\right)$, ammonium $\left(\mathrm{NH}_{4}^{+}\right)$, calcium $\left(\mathrm{Ca}^{2+}\right)$ and magnesium $\left(\mathrm{Mg}^{2+}\right)$ in the solution. Calibration curves were constructed from the peak areas of the chromatograms, which were produced from a series of mixed standards. Samples and blanks collected at both sites were analyzed with replicates and surrogates following standard lab protocols. The relative uncertainty in the mass percentage of sulfate and nitrate, according to the surrogates, was less than $10 \%$.

An energy dispersive X-Ray fluorescence (EDXRF) spectrometry (Epsilon 5 EDXRF; PANalytical B. V., the Netherlands) was used to quantify elements in the samples of the remaining parts of sample filters. Five crustal elements (K, $\mathrm{Ca}, \mathrm{Ti}, \mathrm{Mn}, \mathrm{Fe}$ and $\mathrm{Ba}$ ) and two common anthropogenic trace elements $(\mathrm{Zn}$ and $\mathrm{Pb})$ were quantitatively determined. Analytical uncertainties, as checked by parallel analysis of the NIST standard reference material (SRM-2683), were at or less than $10 \%$ for the detected elements.

\section{Results and discussion}

\subsection{Sulfate}

In the dust plume at the Tengger Desert, the concentration of sulfate ranged from 39 to $59 \mu \mathrm{g} \mathrm{m}^{-3}$. The relative amount of sulfate in the dust samples, i.e., the mass fraction of sulfate in 
Table 2. Concentration (Conc., in $\mu \mathrm{g} \mathrm{m}^{-3}$ ) of TSP $[\mathrm{M}]$, sulfate $\left[\mathrm{SO}_{4}^{2-}\right]$, nitrate $\left[\mathrm{NO}_{3}^{-}\right]$and ammonia $\left[\mathrm{NH}_{4}^{+}\right]$at the desert site in the dust episode. Also included are the relative amounts (R. M., in \%) of the three ions in TSP.

\begin{tabular}{|c|c|c|c|c|c|c|c|}
\hline \multirow[t]{2}{*}{ Samples } & \multirow[t]{2}{*}[\mathrm{M}]{} & \multicolumn{2}{|c|}{$\left[\mathrm{SO}_{4}^{2-}\right]$} & \multicolumn{2}{|c|}{$\left[\mathrm{NO}_{3}^{-}\right]$} & \multicolumn{2}{|c|}{$\left[\mathrm{NH}_{4}^{+}\right]$} \\
\hline & & Conc. & R. M. & Conc. & R. M. & Conc. & R. M. \\
\hline $\mathrm{T} 1$ & 4754 & 59 & 1.2 & 5.9 & 0.12 & 0.27 & $<0.01$ \\
\hline $\mathrm{T} 2$ & 4487 & 54 & 1.2 & 5.1 & 0.11 & 0.22 & $<0.01$ \\
\hline T3 & 3481 & 39 & 1.1 & 3.8 & 0.11 & $\mathrm{ND}^{*}$ & ND \\
\hline Ave. & $4241 \pm 672$ & $51 \pm 10$ & $1.2 \pm 0.1$ & $5.0 \pm 1.1$ & $0.12 \pm 0.11$ & $0.16 \pm 0.14$ & $<0.01$ \\
\hline
\end{tabular}

$*$ Not detected.

the samples, was between 1.1 and $1.2 \%$ and the average was $1.2 \%$ (Table 2). These values were close to the levels of the relative mass ratios of sulfate in TSP or $\mathrm{PM}_{10}$ in samples collected under dust conditions at the Gobi Desert, which were reported in previous studies (Table $\mathrm{S} 1$ ).

The concentration of $\mathrm{SO}_{4}^{2-}$ at $\mathrm{Xi}$ ' an varied in a large range as the front of the dust-loading cyclone was approaching, passing and leaving (Fig. 3). It was $17 \mu \mathrm{g} \mathrm{m}^{-3}$, contributing $4 \%$ of the aerosol mass in the prefrontal air, i.e., before the dust arrival. As the front was passing, the concentration decreased rapidly. In the postfrontal air, the concentration was $3.8 \mu \mathrm{g} \mathrm{m}^{-3}$ right after the front passage, $3.5 \mu \mathrm{g} \mathrm{m}{ }^{-3} 2 \mathrm{~h}$ after the passage and $3.4 \mu \mathrm{g} \mathrm{m}^{-3} 4 \mathrm{~h}$ after the passage. The average in the postfrontal air was $3.5 \mu \mathrm{g} \mathrm{m}^{-3}$. The relative amounts of sulfate in these samples were $0.9,1.1$ and $1.8 \%$, respectively, and the average was about $1.3 \%$. In comparison to that in the prefrontal air, the concentration in the postfrontal air was very small and approximately constant, although the relative amount increased gradually as the front left.

In cyclones moving eastward across northern China, the source and consequently the compositions of major particles in the air before and after cold fronts are different although they are in the same cyclones (Hu et al., 2016; Niu et al., 2011). Prefrontal air usually moves slowly from the south or southwest directions toward the north or northeast and is usually warm and humid. Particles in prefrontal air originate mainly from local or regional areas and they are usually dominated by anthropogenic pollutants ( $\mathrm{Li}$ et al., 2012). The postfrontal air moves more rapidly from the north or northwest direction and is usually cold and dry. Particles in postfrontal air are lifted by the cold fronts of the cyclones at the places they pass, and long-distance-transported dust particles are usually the majority if the cyclones have caused dust storms at the arid and semiarid areas in northwestern China (S. Wang et al., 2005). The cold fronts are the boundaries between the local or regional anthropogenically polluted air and the long-distance-transported air because the movement of air on a synoptic scale is approximately adiabatic; i.e., the air is hardly mixed with the thermodynamically different air it meets, although some small-scale mixing might occur in the front. Aerosol particles at the time of front passage should be

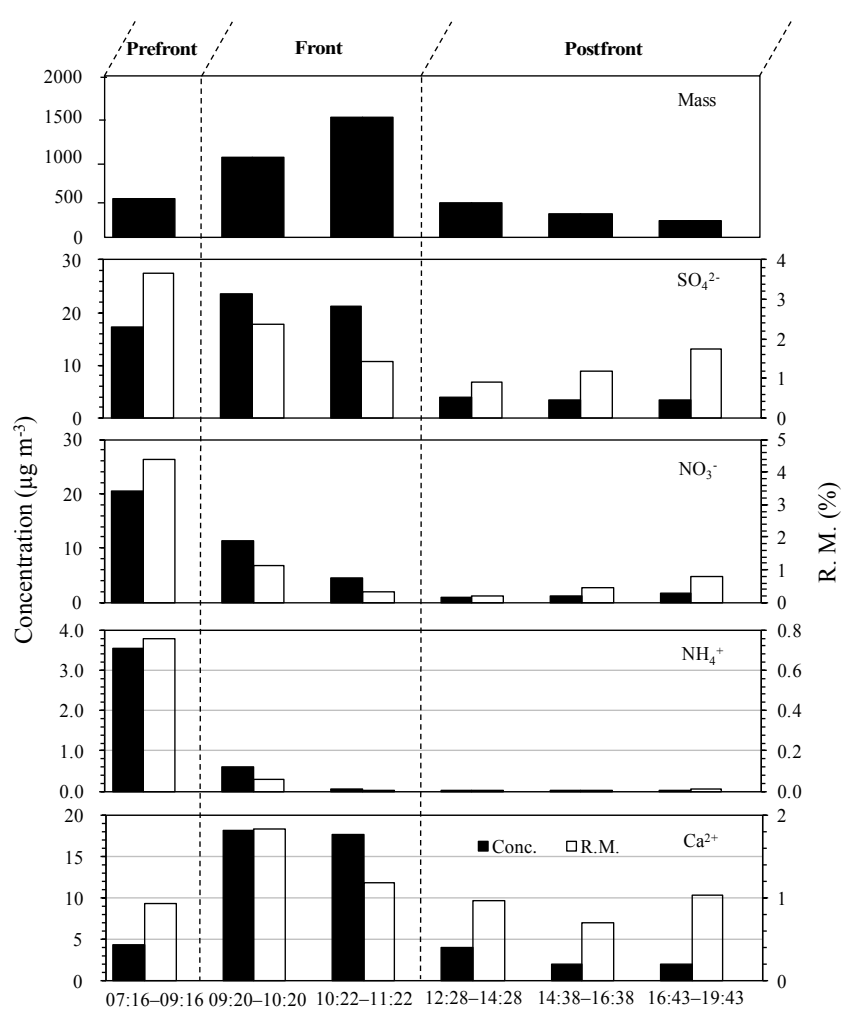

Figure 3. Concentrations of mass, $\mathrm{SO}_{4}^{2-}, \mathrm{NO}_{3}^{-}, \mathrm{NH}_{4}^{+}$and $\mathrm{Ca}^{2+}$ at the Xi'an site during the dust passage. Data for samples between 11:27 and 12:27 BST are not included since the sampler was blown down by wind. The relative amounts (R. M.: the ratios of the ion concentrations to the total mass concentration in percentage) of these ions are also illustrated.

of both local origin and transported from long distances. The rapid decrease in sulfate with the passage of the cold front at Xi'an was consistent with the increase in long-distancetransported dust.

$\mathrm{NH}_{4}^{+}$is one of the major water-soluble species in aerosol particles and can be remarkably enhanced by anthropogenic emissions. We found that its concentration was close to the lowest detection limit in dust samples at the desert site. This fact makes $\mathrm{NH}_{4}^{+}$a good indicator for examining the influence 
Table 3. Mass ratios of $\mathrm{Ca}, \mathrm{Fe}, \mathrm{Ti}, \mathrm{Mn}, \mathrm{Ba}, \mathrm{Zn}$ and $\mathrm{Pb}$ to $\mathrm{Fe}$ in the samples at the two sites.

\begin{tabular}{lrrrrrrr}
\hline Samples & $\mathrm{Ca} / \mathrm{Fe}$ & $\mathrm{K} / \mathrm{Fe}$ & $\mathrm{Ti} / \mathrm{Fe}$ & $\mathrm{Mn} / \mathrm{Fe}$ & $\mathrm{Ba} / \mathrm{Fe}$ & $\mathrm{Zn} / \mathrm{Fe}$ & $\mathrm{Pb} / \mathrm{Fe}$ \\
\hline \multicolumn{7}{l}{ Tengger Desert (24 April 2014) } \\
\hline T1 & 1.47 & 0.54 & 0.084 & 0.023 & 0.013 & 0.003 & 0.0014 \\
T2 & 1.47 & 0.55 & 0.082 & 0.023 & 0.013 & 0.0023 & 0.0011 \\
T3 & 1.57 & 0.57 & 0.086 & 0.024 & 0.012 & 0.002 & 0.0009 \\
\hline Xi'an (1 May 2014) & & & & & & \\
\hline X1 & NA & NA & NA & NA & NA & NA & NA \\
X2 & 1.86 & 0.66 & 0.084 & 0.028 & 0.012 & 0.037 & 0.009 \\
X3 & 2.16 & 0.63 & 0.087 & 0.039 & 0.008 & 0.010 & 0.004 \\
X5 & 1.76 & 0.62 & 0.089 & 0.045 & 0.018 & 0.003 & 0.0009 \\
X6 & 1.44 & 0.63 & 0.092 & 0.031 & 0.015 & 0.003 & 0.0008 \\
X7 & 1.80 & 0.68 & 0.089 & 0.024 & 0.022 & 0.003 & 0.0009 \\
\hline
\end{tabular}

* No enough sample for analysis.

of local or regional anthropogenic particles on the samples observed at Xi' an. The variation in $\mathrm{NH}_{4}^{+}$during the sampling period is also shown in Fig. 3. With the increase in long-distance-transported dust particles, $\mathrm{NH}_{4}^{+}$decreased remarkably as the front was passing the site, and was very low in the frontal air. In the postfrontal air, the $\mathrm{NH}_{4}^{+}$concentration was lower than the detection limit in the first sample and increased slightly in the second and third samples. These results indicate that the composition of particles in the postfrontal air was close to the state of dust particles at the desert areas, whereas the composition was gradually affected by local emissions afterwards. $\mathrm{Zn}$ and $\mathrm{Pb}$ are two common anthropogenic trace elements in urban air. Their ratios to $\mathrm{Fe}$ in the dust samples in the postfrontal air were much lower than those in the prefrontal air and very close to those in the desert air (Table 3), further suggesting the limited influence of pollution on desert dust particles in the postfrontal air.

The relative amount of $\mathrm{SO}_{4}^{2-}$ in dust samples at the desert, 1.1 to $1.2 \%$ in mass, was similar to or even larger than the relative amount at Xi' an (the relative amount in the first sample in the postfrontal air was $0.9 \%$ ). This result indicates that sulfate was rarely produced on dust particles during particle traveled from the desert to the distant urban area. Heterogeneous reactions involving $\mathrm{SO}_{2}$ on mineral particles were the major processes for sulfate production on the particles. The conversion of $\mathrm{SO}_{2}$ to sulfate by heterogeneous reactions on particles is much more efficient under humid conditions than under dry conditions (Usher et al., 2003). The relative humidity was less than $40 \%$ during the dust storm episode in Xi' an (Fig. 2b), which did not favor the formation of sulfate on the surface of mineral components (X. Huang et al., 2014). Moreover, the cold air lofting the dust storm particles was from arid or semiarid areas in the southwestern part of Mongolia where $\mathrm{SO}_{2}$ emissions are usually weak (Fig. S4). The concentration of $\mathrm{SO}_{2}$ in the postfrontal air was nearly close to the detection limit (Fig. S5), which was much smaller than the concentration in the prefrontal air $(\sim 20 \mathrm{ppb})$. Therefore, sulfate was hardly formed on the dust particles due to the lack of $\mathrm{SO}_{2}$ and the dry condition. The postfrontal air had passed some populated areas between the desert and Xi' an where anthropogenic $\mathrm{SO}_{2}$ emissions were usually observed due to human activities (Wang et al., 2011). However, the postfrontal air did not pick up any accumulated air pollutants on the way. Anthropogenic pollutants that might have been taken into the air were those freshly emitted at the moment of the air passage. Such pollutants should not have a considerable influence on the dust. Otherwise, (1) the movement of the dust-loading air should not have been an adiabatic process, which is the reason for the cold front occurrence when arriving at Xi' an, (2) the front should have disappeared, (3) some $\mathrm{NH}_{4}^{+}$should have been present and (4) the sulfate content in the samples at Xi' an should be larger than in the desert sample. The vertical thermodynamic structure near the surface at the two sites became more stable when dust occurred (Fig. S6; from the homepage of Atmospheric Soundings at the University of Wyoming, http://weather.uwyo.edu/upperair/sounding.html), indicating that the dust plume layer established at the dust source was not mixed with air of different chemical (gas and particulate phase) composition from above during the advection.

There was a small amount of sulfate in the dust samples at $\mathrm{Xi}$ 'an. The concentration was much smaller than that in the dust samples at the desert area. However, the relative level of sulfate in the total aerosol mass in the postfrontal air samples $(0.91-1.75 \%)$ was close to and even smaller than that at the desert area (1.19\% on average). This result means that the sulfate in the dust samples at Xi' an was very likely one of the original components of the dust particles, i.e., the socalled soil-derived sulfate in desert dust. It has been found that dust at desert areas contains substantial soil-derived sulfate (Abuduwaili et al., 2008; Sun et al., 2010; X. Wang et al., 2012; Wu et al., 2012; Yabuki et al., 2005; Zhang 
et al., 2009), and sulfate was confirmed in long-distancetransported dust in downstream areas in a small number of studies (Wang et al., 2014, 2007; Q. Wang et al., 2016; Wu et al., 2012). For these reasons, we consider the sulfate detected in the dust samples right after the cold front to be mainly from the desert areas as soil-derived sulfate rather than sulfate produced by chemical conversions on the particle surface when the particles floated in the air.

\subsection{Nitrate}

At the desert site, the $\mathrm{NO}_{3}^{-}$concentration in dust samples was $4-6 \mu \mathrm{g} \mathrm{m}^{-3}$ and the average was $5 \mu \mathrm{g} \mathrm{m}^{-3}$. The relative amount of $\mathrm{NO}_{3}^{-}$ranged between $0.11 \%$ and $0.12 \%$, and the average was $0.12 \%$. At the $\mathrm{Xi}$ 'an site, similar to $\mathrm{SO}_{4}^{2-}$, the concentration of $\mathrm{NO}_{3}^{-}$varied in a large range as the dustloading cyclone passed, with the concentration high in the prefrontal air and low in the postfrontal air. Right after the passage of the cold front (the first sample in the postfrontal air), the concentration of $\mathrm{NO}_{3}^{-}$was $0.9 \mu \mathrm{g} \mathrm{m}^{-3}$ and it occupied $0.2 \%$ of the aerosol mass. These values were close to the levels of the relative mass ratios of nitrate in TSP or $\mathrm{PM}_{10}$ in samples collected under dust conditions at the Gobi Desert, which were reported in previous studies (Table S1).

The relative amount in this sample was about twice that in the desert samples although it was the lowest in the samples at the Xi'an site, indicating that nitrate was likely produced on dust particles during their travel to Xi'an. We assume that the removal of dust particles from the dust plume was independent of the chemical components of dust particles. This assumption is reasonable because the dust plume was relatively dry during its movement from the desert area to the urban area and the settling of dust particles under such conditions depends on particle size only (Zhang, 2008). The concentration of nitrate in dust samples at the desert site was used as a referential value for the part of nitrate originating from the desert areas in the samples at Xi' an areas. The results show that nitrate production on the dust particles was $1.0-1.1 \mathrm{ng} \mathrm{ug}^{-1}$ of dust (approximately $0.1-0.11 \%$ in mass) during the dust movement from the desert to Xi'an. Since the dust plume took approximately $6 \mathrm{~h}$ to move from the desert to $\mathrm{Xi}$ 'an, this increase in nitrate was equivalent to a production rate of $4-5 \mathrm{ng}$ nitrate $\mu \mathrm{g}^{-1}$ of dust per day. Note that this rate should be the maximum rate because not all the nitrate could have been produced on dust particles and the increase in the relative amount of nitrate during the movement of a dust plume from the desert to Xi' an could have been the consequence of possible differences in the removal rates of dust particles and nitrate-containing particles. The estimated rate is much smaller than that in polluted urban air in which secondary nitrate usually accounts for 2-6\% of aerosol loading (Wang et al., 2003) and the production rate is $20-60 \mathrm{ng}$ nitrate $\mu \mathrm{g}^{-1} \mathrm{day}^{-1}$ if we consider the residence time of particles in polluted air to be $24 \mathrm{~h}$.
In general, nitrate on dust particles is produced on the surface via heterogeneous conversions or the uptake of $\mathrm{HNO}_{3}$, which is formed via homogeneous reactions in the atmosphere. Model studies have shown that the latter is the major route for nitrate formation on dust particles, and the contribution of the former route, in particular under dry conditions, is very small (Fairlie et al., 2010; Song and Carmichael, 2001). Desert soil hosts the most abundant natural nitrate minerals on the earth (Walvoord, 2003). Nitrate in desert soil can be reduced to $\mathrm{NO}_{x}$ through microbiological denitrification (Hartley and Schlesinger, 2000) and abiotic thermal decomposition (McCalley and Sparks, 2009). A background-like nitrate, which is about $2-8 \mu \mathrm{g} \mathrm{m}^{-3}$ and assumed to be in the form of nitric acid, has been found in desert air (Wu et al., 2014). Such $\mathrm{HNO}_{3}$ could be absorbed and transformed into nitrate on dust particles during dust movement from the source region to $\mathrm{Xi}$ 'an.

A first-order chemical kinetic equation was used to estimate the uptake of $\mathrm{HNO}_{3}$ during transport:

$c_{t}=c_{0} e^{-k t}$,

where $c_{t}$ is the concentration of $\mathrm{HNO}_{3}$ at transport time $t, c_{0}$ is the initial concentration of $\mathrm{HNO}_{3}$ in the air mass and $k$ is the first-order rate at which the gaseous precursor is taken up by dust. The reaction rate can be calculated as

$k=\frac{1}{4} v_{\mathrm{HNO}_{3}} \gamma_{\mathrm{HNO}_{3}} A_{\mathrm{P}}$,

where $v_{\mathrm{HNO}_{3}}$ is the mean molecular speed of $\mathrm{HNO}_{3}$ and is taken as $3.0 \times 10^{4} \mathrm{~cm} \mathrm{~s}^{-1}$ (Fairlie et al., 2010); $\gamma_{\mathrm{HNO}_{3}}$ is the reactive uptake coefficient for $\mathrm{HNO}_{3}$ on dust particles. Measurements in laboratory experiments showed that the uptake coefficient of $\mathrm{HNO}_{3}$ on mineral dust ranged from $5.2 \times 10^{-5}$ (Underwood et al., 2001) to $5 \times 10^{-3}$ (Song et al., 2007). The coefficient was a function of relative humidity (Vlasenko et al., 2006) and estimated to be $\sim 2 \times 10^{-4}$ under experimental conditions of 30-40\% relative humidity (Fairlie et al., 2010). $A_{\mathrm{P}}\left(\mathrm{cm}^{2} \mathrm{~cm}^{-3}\right)$ is the total surface area of dust particles and is determined by the loading of dust particles and their specific surface area. Surface area analysis has shown the specific area of Gobi dust to be approximately $110 \mathrm{~cm}^{2} \mathrm{mg}^{-1}$ (Underwood et al., 2001). The dust load by mass (in $\mu \mathrm{g} \mathrm{m}^{-3}$ ) initially at the Tengger Desert for the dust plume observed at $\mathrm{Xi}$ ' an is estimated to be $1187 \mathrm{\mu g} \mathrm{m}^{-3}$ based on the dust load of the first sample of postfrontal air $\left(415.4 \mu \mathrm{g} \mathrm{m}^{-3}\right)$ and the relationship between dust concentration and their transport distance as suggested by Mori et al. (2002).

The reaction rate for $\mathrm{HNO}_{3}$ gas uptake on mineral dust was $1.96 \times 10^{-4} \mathrm{~s}^{-1}$. The concentration of $\mathrm{HNO}_{3}$ after $6 \mathrm{~h}$ reduced to $\sim 1 \%$ of the initial concentration, indicating that almost all $\mathrm{HNO}_{3}$ could be transformed into nitrate on the dust particles during their transport. As described above, nitrate produced on the dust samples was $0.1-0.11 \%$, indicating that the concentration of $\mathrm{NO}_{3}^{-}$increased by $1.2-1.3 \mu \mathrm{g} \mathrm{m}^{-3}$. To 
Table 4. The relative amounts (\%) of nitrate, sulfate and ammonia in $\mathrm{TSP}$ or $\mathrm{PM}_{2.5}$ in postfrontal air during dust storms at downwind Chinese cities.

\begin{tabular}{lrrrll}
\hline Site & $\mathrm{SO}_{4}^{2-}$ & $\mathrm{NO}_{3}^{-}$ & $\mathrm{NH}_{4}^{+}$ & Remarks & References \\
\hline Xi'an & 0.91 & 0.22 & NA & TSP (1 May 2014) & This study \\
Xi'an & 1.05 & 0.21 & 0.09 & TSP (9 March 2013) & Wang et al. (2014) \\
Beijing & 0.75 & 0.08 & 0.05 & TSP (22 March 2002) & Zhao et al. (2007) \\
Shanghai & 2.7 & 1.4 & 0.7 & $\mathrm{PM}_{2.5}(20-21$ March 2010) & Wang et al. (2013) \\
\hline
\end{tabular}

produce this amount of nitrate, the $\mathrm{HNO}_{3}$ concentration in the dust-loading air should be approximately $1.2-1.3 \mu \mathrm{g} \mathrm{m}^{-3}$ on average. Unfortunately, there are no data on nitric acid in the air over the Tengger Desert for further comparison. The concentration of nitrate (including particulate and gaseous phases) at the Taklimakan Desert in northwestern China was 2-8 $\mu \mathrm{g} \mathrm{m}^{-3}$ (Wu et al., 2014), which was in the same range as found that for the nitrate concentration in the dust at our Xi' an site.

\subsection{Intercomparisons and implications}

There have been studies on dust-associated sulfate and nitrate in aerosol particles downwind of areas in mainland China (Table 4). Zhao et al. (2007) investigated the evolution of air pollutants when an extremely strong dust storm from the Gobi Desert near the China-Mongolia border passed Beijing and confirmed the rapid decrease in sulfate and nitrate after the passage of the dust-associated cold front. The relative amounts of sulfate and nitrate in the postfrontal air were 0.77 and $0.08 \%$, respectively, which were close to the relative amounts of the salts we observed at the desert site and the Xi' an site in this study. Wang et al. (2014) reported hourly sulfate and nitrate in aerosols at Xi' an during a dust storm period on 9 March 2013. The dust storm also originated from the Gobi Desert in the southwestern part of Mongolia, similar to the dust cases in this study. After the passage of the cold front, the relative amounts of sulfate and nitrate were 1.05 and $0.21 \%$, respectively, which were also very close to the results of this study.

A number of studies in China reported that dust particles significantly enhanced the formation of sulfate and nitrate when dust plumes advected over urban areas (Li and Shao, 2009; Li et al., 2014; Nie et al., 2012; Qi et al., 2006; Sheng et al., 2003; Wang et al., 2013; Zhao et al., 2011, 2007), which is very different from the conclusions of this study. We carefully examined the available meteorological records for the dust episodes in those studies. In cases of cold-frontassociated dust (Li et al., 2014; Qi et al., 2006; Sheng et al., 2003; Zhao et al., 2007), the samples used in those studies were collected repeatedly in pre-fixed time periods without a careful consideration of the time of dust arrival. That means the samples were not separately collected from defined prefrontal air and postfrontal air masses, and some samples used for analysis included particles from both prefrontal air and postfrontal air. The results from such samples would show the presence of substantial sulfate and nitrate. However, the sulfate and nitrate must have been contributed by particles in prefrontal air, which should be from local or regional areas and abundant in sulfate and nitrate. In a recent publication about the passage of a dust storm over Beijing with a high time resolution, online records clearly demonstrated the separation of the prefrontal pollutants and the postfrontal dust plume (Hu et al., 2016), further indicating the necessity of separating particles in prefrontal air and postfrontal air for an accurate description of salt origin in dust samples.

In addition, mineral ions or crustal elements (e.g., the $\mathrm{Ca}^{2+}$ ion or elemental $\mathrm{Al}$ ) have frequently been applied as the indicators of mineral dust in studies (Nie et al., 2012; Zhao et al., 2007). Samples with the highest loading of mass or crustal compositions (e.g., $\mathrm{Ca}^{2+}, \mathrm{Al}$ ) were frequently regarded as samples of long-distance-transported dust. However, the samples in those studies were actually collected from the front air, as we described above, and were a mixture of long-distance-transported dust particles and locally and regionally originated aerosols. For example, in the study of Zhao et al. (2007), the mineral to TSP (total suspended particulate matter) ratios in samples of the highest TSP loading were significantly lower than those in samples collected after the occurrence of maximum aerosol loading, indicating that the samples at the highest TSP moment were not dust particles from desert areas only. The indicators of mineral crustal ions or elements (e.g., the $\mathrm{Ca}^{2+}$ ion or elemental $\mathrm{Al}$ ) may actually cause large uncertainties in explaining origins and sometimes even misunderstandings about the origins of aerosol particles. The reason is that, in addition to road dust and construction dust, coal burning is a major source of mineral components in aerosols in China and emits particulate matter that is abundant in mineral elements such as $\mathrm{Si}, \mathrm{Al}$, $\mathrm{Ca}$ and $\mathrm{Fe}$ (Chen et al., 2012). Coal burning emissions have been proven to cause significant air pollution in China (Cao et al., 2005; Wang et al., 2015; H. Wang et al., 2016). Anthropogenic pollutants are usually present in prefrontal air. If only the presence of substantial mineral elements such as $\mathrm{Ca}, \mathrm{Al}$ or $\mathrm{Si}$ is used as the indicator of the occurrence of mineral dust particles from desert areas, anthropogenic pollutants such as road dust and particles emitted from coal burning will be categorized as desert dust particles. Such an examination would lead to a result indicating the occurrence 
of substantial sulfate- and nitrate-containing dust particles in samples.

In many cases, dust was observed in cyclonic disturbances with weak fronts or without fronts (Cao et al., 2003; Nie et al., 2012; Wang et al., 2013). Cold fronts could not be confirmed clearly at places of dust arrival in those studies. The cases usually occur in the southern parts of China after the cold and dry air from the north lose their adiabatic state, and the postfrontal air arriving at such places has, to an extent, mixed with the local and regional air. Samples of aerosol particles after dust arrival at such places contain both long-distance-transported dust particles and locally or regionally emitted pollutants. For example, Wang et al. (2013) reported the occurrence of nitrate and sulfate in particles during two extreme dust storms in Shanghai, a megacity in eastern China, from 20 to 22 March 2010 and from 26 to 27 April 2010. Weather charts (see Fig. 8) showed the consecutive transport of anthropogenic air masses and dust storm plumes to Shanghai during the dust periods either with a cold front arrival (the previous case; equivalent to dust case with front in this study) or by the stimulation of a cold front event even though the front did not extend to Shanghai (the latter case; dust case without front). The relative amounts of sulfate and nitrate in samples at Shanghai during this period were 2.7 and $1.4 \%$ in the previous case and 9 and $5.9 \%$ in the latter case. Anthropogenic sulfate and nitrate in particles from the local and regional areas in the latter case would have appeared in the samples although they were not produced on dust particles from desert areas.

To further examine the situation of previously reported sulfate and nitrate formation on dust storm particles at populated areas in eastern China, we investigated all published papers we found on this subject and carefully checked the records of sample collection and the available meteorological conditions when the samples were collected in those studies from the papers and official public websites for historical meteorological records. The papers were separated into three groups according to the records and meteorological conditions, as mentioned above. The first group includes papers in which the sample collection records were vague, and we are unable to make clear it clear whether the samples were dominated by desert dust particles or contained a large fraction of locally emitted particles (Table S2a). It is uncertain whether the sulfate and nitrate reported in those papers were really on desert dust particles or not. The second group includes papers in which the sample collection was started before the arrival of the fronts of dust-loading cyclones or the fronts had disappeared and front-associated dust-loading air had mixed with locally polluted air (Table S2b). That means the samples in the studies contained not only long-distance-transported desert dust particles but also locally emitted mineral particles, such as road dust, construction dust and fly ashes. In such samples, the sulfate and nitrate must have been substantially contributed by locally emitted mineral particles, as we discussed above. The third group includes papers in which the results from samples of locally or regionally originated particles in prefrontal air and from samples of long-distancetransported desert dust particles in postfrontal air can be identified (Table S2c). The production of sulfate and nitrate in the postfrontal dust samples was all very limited, and the production in prefrontal samples was significant, which is consistent with our results in this study.

\section{Conclusion}

Dust particles were collected at the Tengger Desert and Xi' an during two dust storm periods. Meteorological records showed that these two dust storms originated from the same source region and had similar transport routes. The comparison of sulfate and nitrate of dust aerosol at the two places indicated that the production of sulfate and nitrate on dust particles following cold fronts was limited when the dust moved from the desert to populated areas. The adiabatic process of the dust-loading air movement was most likely the reason for the absence of sulfate formation, and the uptake of $\mathrm{HNO}_{3}$ was responsible for the small nitrate production.

The significant sulfate and nitrate in dust storm periods in China reported in previous studies did not link to reactions on the dust surface for the most part. They were likely from locally emitted and urban mineral particles, in addition to soilderived sulfate. The major reason is that in those studies the air from which the samples were collected had been significantly influenced by local emissions. Without a proper evaluation of the contribution of sulfate and nitrate in the samples by locally emitted and urban mineral particles, i.e., nondesert mineral particles, it is not safe to attribute all the detected sulfate and nitrate to production on dust storm particles.

The results of this study are from the comparison of dust particles in two dust storms: one at the dust source area and another at an urban area after long-distance transport. Although the thermodynamic structure of the dust-loading air in the two cases was similar and comparable, data from multiple cases of the same dust storms at desert areas and downwind populated areas are needed to make the present conclusions more accurate and confident. In addition, the conclusions were derived for front-associated dust storm particles. The adiabatic nature of the postfrontal air during its long-distance movement kept the air dry and hardly polluted by accumulated anthropogenic pollutants from the areas it passed. There are other types of airborne dust particles in China, such as floating dust. The movement of air-loading floating dust is usually slow and not adiabatic, and the air is usually well mixed with locally emitted pollutants, which is very different from postfrontal air. It can be expected that floating dust particles could be more frequently changed to sulfate and nitrate carriers via surface chemical reactions than front-associated dust storm particles in urban areas. However, how to separate the sulfate and nitrate produced on floating dust particles from those produced on locally emitted mineral particles 
is still a big challenge in field observations because floating dust particles and locally emitted mineral particles coexist in urban air when floating dust occurs.

Data availability. The underlying research data can be accessed by contacting the corresponding author (Feng $\mathrm{Wu}$, kurt_wf@ieecas.cn).

\section{The Supplement related to this article is available online at https://doi.org/10.5194/acp-17-14473-2017- supplement.}

Author contributions. FW and DZ designed the experiments; XG, YX and TZ collected the samples and analyzed them. JC, YC and HL reviewed and commented on the paper; FW and DZ prepared the paper with contributions from all coauthors.

Competing interests. The authors declare that they have no conflict of interest.

Special issue statement. This article is part of the special issue "Anthropogenic dust and its climate impact". It is not associated with a conference.

Acknowledgements. This work was supported by the "Strategic Priority Research Program" of the Chinese Academy of Sciences (grant no. XDB05000000) and the NNSF of China (grant no. 40872211). It was also partly funded by a Grant-in-Aid for Scientific Research (B) of JSPS (no. 16H02942). The authors thank Jay Melton and Morrow Stewart for reviewing the grammar and language. We also thank Shuyu Zhao for providing the figure for $\mathrm{SO}_{2}$ emission distributions.

Edited by: Jianping Huang

Reviewed by: Barry Huebert and three anonymous referees

\section{References}

Abuduwaili, J., Gabchenko, M. V., and Junrong, X.: Eolian transport of salts - A case study in the area of Lake Ebinur (Xinjiang, Northwest China), J. Arid Environ., 72, 1843-1852, https://doi.org/10.1016/j.jaridenv.2008.05.006, 2008.

Bates, T. S., Quinn, P. K., Coffman, D. J., and Covert, D. S.: Marine boundary layer dust and pollutant transport associated with the passage of a frontal system over eastern Asia, J. Geophys. Res., 109, D19S19, https://doi.org/10.1029/2003jd004094, 2004.

Bauer, S. E. and Koch, D.: Impact of heterogeneous sulfate formation at mineral dust surfaces on aerosol loads and radiative forcing in the Goddard Institute for Space Studies general circulation model, J. Geophys. Res., 110, D17202, https://doi.org/10.1029/2005JD005870, 2005.
Bi, J., Huang, J., Fu, Q., Wang, X., Shi, J., Zhang, W., Huang, Z., and Zhang, B.: Toward characterization of the aerosol optical properties over Loess Plateau of Northwestern China, J. Quant. Spectrosc. Ra., 112, 346-360, https://doi.org/10.1016/j.jqsrt.2010.09.006, 2011.

Cao, J. J., Lee, S. C., Zheng, X. D., Ho, K. F., Zhang, X. Y., Guo, H., Chow, J. C., and Wang, H. B.: Characterization of dust storms to Hong Kong in April 1998, Water Air Soil Poll., 3, 213-229, 2003.

Cao, J. J., Wu, F., Chow, J. C., Lee, S. C., Li, Y., Chen, S. W., An, Z. S., Fung, K. K., Watson, J. G., Zhu, C. S., and Liu, S. X.: Characterization and source apportionment of atmospheric organic and elemental carbon during fall and winter of 2003 in Xi' an, China, Atmos. Chem. Phys., 5, 3127-3137, https://doi.org/10.5194/acp5-3127-2005, 2005.

Chen, H., Laskin, A., Baltrusaitis, J., Gorski, C. A., Scherer, M. M., and Grassian, V. H.: Coal fly ash as a source of iron in atmospheric dust, Environ. Sci. Technol., 46, 2112-2120, https://doi.org/10.1021/es204102f, 2012.

Denjean, C., Caquineau, S., Desboeufs, K., Laurent, B., Maille, M., Quiñones Rosado, M., Vallejo, P., Mayol-Bracero, O. L., and Formenti, P.: Long-range transport across the Atlantic in summertime does not enhance the hygroscopicity of African mineral dust, Geophys. Res. Lett., 42, 7835-7843, https://doi.org/10.1002/2015GL065693, 2015.

Dentener, F. J., Carmichael, G. R., Zhang, Y., Lelieveld, J., and Crutzen, P. J.: Role of mineral aerosol as a reactive surface in the global troposphere, J. Geophys. Res., 101, 22869-22889, https://doi.org/10.1029/96JD01818, 1996.

Dong, X., Fu, J. S., Huang, K., Tong, D., and Zhuang, G.: Model development of dust emission and heterogeneous chemistry within the Community Multiscale Air Quality modeling system and its application over East Asia, Atmos. Chem. Phys., 16, 8157-8180, https://doi.org/10.5194/acp-16-8157-2016, 2016.

Fairlie, T. D., Jacob, D. J., Dibb, J. E., Alexander, B., Avery, M. A., van Donkelaar, A., and Zhang, L.: Impact of mineral dust on nitrate, sulfate, and ozone in transpacific Asian pollution plumes, Atmos. Chem. Phys., 10, 3999-4012, https://doi.org/10.5194/acp-10-3999-2010, 2010.

Fu, Q., Thorsen, T. J., Su, J., Ge, J. M., and Huang, J. P.: Test of Miebased single-scattering properties of non-spherical dust aerosols in radiative flux calculations, J. Quant. Spectrosc. Ra., 110, 1640-1653, https://doi.org/10.1016/j.jqsrt.2009.03.010, 2009.

Hartley, A. E. and Schlesinger, W. H.: Environmental controls on nitric oxide emission from northern Chihuahuan desert soils, Biogeochemistry, 50, 279-300, 2000.

Hu, W., Niu, H., Zhang, D., Wu, Z., Chen, C., Wu, Y., Shang, D., and $\mathrm{Hu}, \mathrm{M}$.: Insights into a dust event transported through Beijing in spring 2012: Morphology, chemical composition and impact on surface aerosols, Sci. Total Environ., 565, 287-298, https://doi.org/10.1016/j.scitotenv.2016.04.175, 2016.

Huang, K., Zhuang, G., Li, J., Wang, Q., Sun, Y., Lin, Y., and Fu, J. S.: Mixing of Asian dust with pollution aerosol and the transformation of aerosol components during the dust storm over China in spring 2007, J. Geophys. Res., 115, D00K13, https://doi.org/10.1029/2009JD013145, 2010.

Huang, R.-J., Zhang, Y., Bozzetti, C., Ho, K.-F., Cao, J.-J., Han, Y., Daellenbach, K. R., Slowik, J. G., Platt, S. M., Canonaco, F., Zotter, P., Wolf, R., Pieber, S. M., Bruns, E. A., Crippa, M., Ciarelli, 
G., Piazzalunga, A., Schwikowski, M., Abbaszade, G., SchnelleKreis, J., Zimmermann, R., An, Z., Szidat, S., Baltensperger, U., Haddad, I. E., and Prevot, A. S. H.: High secondary aerosol contribution to particulate pollution during haze events in China, Nature, 514, 218-222, https://doi.org/10.1038/nature13774, 2014.

Huang, X., Song, Y., Zhao, C., Li, M., Zhu, T., Zhang, Q., and Zhang, X.: Pathways of sulfate enhancement by natural and anthropogenic mineral aerosols in China, J. Geophys. Res.-Atmos., 119, 14165-14179, https://doi.org/10.1002/2014JD022301, 2014.

Li, J., Wang, Z., Zhuang, G., Luo, G., Sun, Y., and Wang, Q.: Mixing of Asian mineral dust with anthropogenic pollutants over East Asia: a model case study of a superduststorm in March 2010, Atmos. Chem. Phys., 12, 7591-7607, https://doi.org/10.5194/acp-12-7591-2012, 2012.

Li, W. J. and Shao, L. Y.: Observation of nitrate coatings on atmospheric mineral dust particles, Atmos. Chem. Phys., 9, 18631871, https://doi.org/10.5194/acp-9-1863-2009, 2009.

Li, W. J., Shao, L. Y., Shi, Z. B., Chen, J. M., Yang, L. X., Yuan, Q., Yan, C., Zhang, X. Y., Wang, Y. Q., Sun, J. Y., Zhang, Y. M., Shen, X. J., Wang, Z. F., and Wang, W. X.: Mixing state and hygroscopicity of dust and haze particles before leaving Asian continent, J. Geophys. Res.-Atmos., 119, 1044-1059, https://doi.org/10.1002/2013JD021003, 2014.

McCalley, C. K. and Sparks, J. P.: Abiotic gas formation drives nitrogen loss from a desert ecosystem, Science, 326, 837-840, https://doi.org/10.1126/science.1178984, 2009.

Meskhidze, N.: Iron mobilization in mineral dust: Can anthropogenic $\mathrm{SO}_{2}$ emissions affect ocean productivity?, Geophys. Res. Lett., 30, 2085, https://doi.org/10.1029/2003gl018035, 2003.

Mori, I.: Change in size distribution and chemical composition of kosa (Asian dust) aerosol during long-range transport, Atmos. Environ., 37, 4253-4263, https://doi.org/10.1016/S13522310(03)00535-1, 2003

Mori, I., Nishikawa, M., Quan, H., and Morita, M.: Estimation of the concentration and chemical composition of kosa aerosols at their origin, Atmos. Environ., 36, 4569-4575, https://doi.org/10.1016/s1352-2310(02)00489-2, 2002.

Nie, W., Wang, T., Xue, L. K., Ding, A. J., Wang, X. F., Gao, X. M., Xu, Z., Yu, Y. C., Yuan, C., Zhou, Z. S., Gao, R., Liu, X. H., Wang, Y., Fan, S. J., Poon, S., Zhang, Q. Z., and Wang, W. X.: Asian dust storm observed at a rural mountain site in southern China: chemical evolution and heterogeneous photochemistry, Atmos. Chem. Phys., 12, 11985-11995, https://doi.org/10.5194/acp-12-11985-2012, 2012.

Nishikawa, M., Kanamori, S., Kanamori, N., and Mizoguchi, T.: Kosa aerosol as eolian carrier of anthropogenic material, Sci. Total Environ., 107, 13-27, https://doi.org/10.1016/00489697(91)90247-C, 1991.

Niu, H., Shao, L., and Zhang, D.: Aged status of soot particles during the passage of a weak cyclone in Beijing, Atmos. Environ., 45, 2699-2703, https://doi.org/10.1016/j.atmosenv.2011.02.056, 2011.

Qi, J., Li, X., Feng, L., and Zhang, M.: Characterization of dust and non-dust aerosols with SEM/EDX, J. Ocean Univ. China, 5, 85-90, https://doi.org/10.1007/BF02919381, 2006.

Ro, C.-U., Hwang, H., Kim, H., Chun, Y., and Van Grieken, R.: Single-Particle Characterization of Four "Asian Dust" Sam- ples Collected in Korea, Using Low-ZParticle Electron Probe X-ray Microanalysis, Environ. Sci. Technol., 39, 1409-1419, https://doi.org/10.1021/es049772b, 2005.

Semeniuk, T. A., Wise, M. E., Martin, S. T., Russell, L. M., and Buseck, P. R.: Water uptake characteristics of individual atmospheric particles having coatings, Atmos. Environ., 41, 62256235, https://doi.org/10.1016/j.atmosenv.2007.04.001, 2007.

Sheng, L., Geng, M., Wang, Y., Gao, H., Shi, G., and Yu, P.: Effects of dust storms on atmospheric aerosols in Qingdao in spring 2002, Research of Environmental Sciences, 16, 11-13, 2003 (in Chinese).

Sokolik, I. N. and Toon, O. B.: Direct radiative forcing by anthropogenic airborne mineral aerosols, Nature, 381, 681-683, https://doi.org/10.1038/381681a0, 1996.

Song, C. H. and Carmichael, G. R.: A three-dimensional modelling investigation of the evolution processes of dust and seasalt particles in east Asia, J. Geophys. Res., 106, 18131-18154, https://doi.org/10.1029/2000JD900352, 2001.

Song, C. H., Maxwell-Meier, K., Weber, R. J., Kapustin, V., and Clarke, A.: Dust composition and mixing state inferred from airborne composition measurements during ACE-Asia C130 Flight \#6, Atmos. Environ., 39, 359-369, https://doi.org/10.1016/j.atmosenv.2004.08.046, 2005.

Song, C. H., Kim, C. M., Lee, Y. J., Carmichael, G. R., Lee, B. K., and Lee, D. S.: An evaluation of reaction probabilities of sulfate and nitrate precursors onto East Asian dust particles, J. Geophys. Res., 112, D18206, https://doi.org/10.1029/2006JD008092, 2007.

Sun, Y., Zhuang, G., Yuan, H., Zhang, X., and Guo, J.: Characteristics and sources of 2002 super dust storm in Beijing, Chinese Sci Bull., 49, 698-705, https://doi.org/10.1007/BF03184268, 2004.

Sun, Y., Zhuang, G., Huang, K., Li, J., Wang, Q., Wang, Y., Lin, Y., Fu, J. S., Zhang, W., Tang, A., and Zhao, X.: Asian dust over northern China and its impact on the downstream aerosol chemistry in 2004, J. Geophys. Res., 115, D00K09, https://doi.org/10.1029/2009JD012757, 2010.

Tegen, I., Lacis, A. A., and Fung, I.: The influence on climate forcing of mineral aerosols from disturbed soils, Nature, 380, 419422, https://doi.org/10.1038/380419a0, 1996.

Tsai, F., Tu, J.-Y., Hsu, S.-C., and Chen, W. N.: Case study of the Asian dust and pollutant event in spring 2006: Source, transport, and contribution to Taiwan, Sci. Total Environ., 478, 163-174, https://doi.org/10.1016/j.scitotenv.2014.01.072, 2014.

Underwood, G. M., Li, P., Al-Abadleh, H., and Grassian, V. H.: A Knudsen Cell Study of the Heterogeneous Reactivity of Nitric Acid on Oxide and Mineral Dust Particles, J. Phys. Chem. A, 105, 6609-6620, https://doi.org/10.1021/jp002223h, 2001.

Usher, C. R., Michel, A. E., and Grassian, V. H.: Reactions on mineral dust, Chem. Rev., 103, 4883-4940, https://doi.org/10.1021/cr020657y, 2003.

Vlasenko, A., Sjogren, S., Weingartner, E., Stemmler, K., Gäggeler, H. W., and Ammann, M.: Effect of humidity on nitric acid uptake to mineral dust aerosol particles, Atmos. Chem. Phys., 6, 21472160, https://doi.org/10.5194/acp-6-2147-2006, 2006.

Walvoord, M. A.: A reservoir of nitrate beneath desert soils, Science, 302, 1021-1024, https://doi.org/10.1126/science.1086435, 2003.

Wang, F., Xu, D., Shi, J., and Chen, X.: Numerical analysis of interaction of $\mathrm{SO}_{2}$ emission among 19 cities along the Middle-up 
stream of Yellow River and their contribution to Beijing city, Sci. Technol. Rev., 29, 25-29, 2011.

Wang, G., Cheng, S., Li, J., Lang, J., Wen, W., Yang, X., and Tian, L.: Source apportionment and seasonal variation of $\mathrm{PM}_{2.5}$ carbonaceous aerosol in the Beijing-TianjinHebei Region of China, Environ. Monit. Assess., 187, 143, https://doi.org/10.1007/s10661-015-4288-x, 2015.

Wang, G. H., Wang, H., Yu, Y. J., Gao, S. X., Feng, J. F., Gao, S. T., and Wang, L. S.: Chemical characterization of water-soluble components of $\mathrm{PM}_{10}$ and $\mathrm{PM}_{2.5}$ atmospheric aerosols in five locations of Nanjing, China, Atmos. Environ., 37, 2893-2902, https://doi.org/10.1016/S1352-2310(03)00271-1, 2003.

Wang, G. H., Cheng, C. L., Huang, Y., Tao, J., Ren, Y. Q., Wu, F., Meng, J. J., Li, J. J., Cheng, Y. T., Cao, J. J., Liu, S. X., Zhang, T., Zhang, R., and Chen, Y. B.: Evolution of aerosol chemistry in Xi'an, inland China, during the dust storm period of 2013 - Part 1: Sources, chemical forms and formation mechanisms of nitrate and sulfate, Atmos. Chem. Phys., 14, 11571-11585, https://doi.org/10.5194/acp-14-11571-2014, 2014.

Wang, H., An, J., Cheng, M., Shen, L., Zhu, B., Li, Y., Wang, Y., Duan, Q., Sullivan, A., and Xia, L.: One year online measurements of water-soluble ions at the industrially polluted town of Nanjing, China: Sources, seasonal and diurnal variations, Chemosphere, 148, 526-536, https://doi.org/10.1016/j.chemosphere.2016.01.066, 2016.

Wang, J., Xu, X., Henze, D. K., Zeng, J., Ji, Q., Tsay, S.-C., and Huang, J.: Top-down estimate of dust emissions through integration of MODIS and MISR aerosol retrievals with the GEOS-Chem adjoint model, Geophys. Res. Lett., 39, L08802, https://doi.org/10.1029/2012GL051136, 2012.

Wang, L., Du, H., Chen, J., Zhang, M., Huang, X., Tan, H., Kong, L., and Geng, F.: Consecutive transport of anthropogenic air masses and dust storm plume: Two case events at Shanghai, China, Atmos. Res., 127, 22-33, https://doi.org/10.1016/j.atmosres.2013.02.011, 2013.

Wang, Q., Zhuang, G., Huang, K., Liu, T., Lin, Y., Deng, C., Fu, Q., Fu, J. S., Chen, J., Zhang, W., and Yiming, M.: Evolution of particulate sulfate and nitrate along the Asian dust pathway: Secondary transformation and primary pollutants via long-range transport, Atmos. Res., 169, 86-95, https://doi.org/10.1016/j.atmosres.2015.09.013, 2016.

Wang, S., Wang, J., Zhou, Z., and Shang, K.: Regional characteristics of three kinds of dust storm events in China, Atmos. Environ., 39, 509-520, https://doi.org/10.1016/j.atmosenv.2004.09.033, 2005.

Wang, X., Hua, T., Zhang, C., Lang, L., and Wang, H.: Aeolian salts in Gobi deserts of the western region of Inner Mongolia: Gone with the dust aerosols, Atmos. Res., 118, 1-9, https://doi.org/10.1016/j.atmosres.2012.06.003, 2012.

Wang, Y., Zhuang, G., Sun, Y., and An, Z.: Water-soluble part of the aerosol in the dust storm season - evidence of the mixing between mineral and pollution aerosols, Atmos. Environ., 39, 7020-7029, https://doi.org/10.1016/j.atmosenv.2005.08.005, 2005.

Wang, Y., Zhuang, G., Tang, A., Zhang, W., Sun, Y., Wang, Z., and An, Z.: The evolution of chemical components of aerosols at five monitoring sites of China during dust storms, Atmos. Environ., 41, 1091-1106, https://doi.org/10.1016/j.atmosenv.2006.09.015, 2007.
Wu, F., Zhang, D., Cao, J., Xu, H., and An, Z.: Soil-derived sulfate in atmospheric dust particles at Taklimakan desert, Geophys. Res. Lett., 39, L24802, https://doi.org/10.1029/2012GL054406, 2012.

Wu, F., Zhang, D., Cao, J., Zhang, T., and An, Z.: Backgroundlike nitrate in desert air, Atmos. Environ., 84, 39-43, https://doi.org/10.1016/j.atmosenv.2013.11.043, 2014.

$\mathrm{Wu}$, P.-M. and Okada, K.: Nature of coarse nitrate particles in the atmosphere - A single particle approach, Atmos. Environ., 28, 2053-2060, https://doi.org/10.1016/1352-2310(94)90473-1, 1994.

Yabuki, S., Mikami, M., Nakamura, Y., Kanayama, S., Fu, F., Liu, M., and Zhou, H.: The characteristics of atmospheric aerosol at Aksu, an Asian dust-source region of North-West China: A summary of observations over the three years from March 2001 to April 2004, J. Meteor. Soc. Jpn., 83A, 45-72, https://doi.org/10.2151/jmsj.83A.45, 2005.

Zhang, D.: Effect of sea salt on dust settling to the ocean, Tellus, 68B, 641-646, https://doi.org/10.1111/j.16000889.2008.00358.x, 2008.

Zhang, D. and Iwasaka, Y.: Nitrate and sulfate in individual Asian dust-storm particles in Beijing, China in Spring of 1995 and 1996, Atmos. Environ., 33, 3213-3223, https://doi.org/10.1016/S1352-2310(99)00116-8, 1999.

Zhang, D., Iwasaka, Y., Shi, G., Zang, J., Hu, M., and Li, C.: Separated status of the natural dust plume and polluted air masses in an Asian dust storm event at coastal areas of China, J. Geophys. Res., 110, D06302, https://doi.org/10.1029/2004JD005305, 2005.

Zhang, T., Cao, J. J., Tie, X. X., Shen, Z. X., Liu, S. X., Ding, H., Han, Y. M., Wang, G. H., Ho, K. F., Qiang, J., and Li, W. T.: Water-soluble ions in atmospheric aerosols measured in $\mathrm{Xi}$ 'an, China: Seasonal variations and sources, Atmos. Res., 102, 110 119, https://doi.org/10.1016/j.atmosres.2011.06.014, 2011.

Zhang, X., Zhuang, G., Yuan, H., Rahn, K. A., Wang, Z., and An, Z.: Aerosol particles from dried salt-lakes and saline soils carried on dust storms over Beijing, Terr. Atmos. Ocean. Sci., 20, 619628, https://doi.org/10.3319/TAO.2008.07.11.03(A), 2009.

Zhang, X. Y., Gong, S. L., Shen, Z. X., Mei, F. M., Xi, X. X., Liu, L. C., Zhou, Z. J., Wang, D., Wang, Y. Q., and Cheng, Y.: Characterization of soil dust aerosol in China and its transport and distribution during 2001 ACE-Asia: 1. Network observations, J. Geophys. Res., 108, 4261, https://doi.org/10.1029/2002JD002632, 2003.

Zhang, Y. and Carmichael, G. R.: The role of mineral aerosol in tropospheric chemistry in East Asia - A model study, J. Appl. Meteor., 38, 353-366, https://doi.org/10.1175/15200450(1999)038<0353:tromai>2.0.co;2, 1999.

Zhao, J., Zhang, F., Xu, Y., Chen, J., Yin, L., Shang, X., and Xu, L.: Chemical characteristics of particulate matter during a heavy dust episode in a coastal city, Xiamen, 2010, Aerosol Air Qual. Res., 11, 299-308, https://doi.org/10.4209/aaqr.2010.09.0073, 2011.

Zhao, X., Zhuang, G., Wang, Z., Sun, Y., Wang, Y., and Yuan, H.: Variation of sources and mixing mechanism of mineral dust with pollution aerosol - revealed by the two peaks of a super dust storm in Beijing, Atmos. Res., 84, 265-279, https://doi.org/10.1016/j.atmosres.2006.08.005, 2007. 